\title{
Design and Research of Electron Cyclotron Resonance Heating and Current Dive System on HL-2M Tokamak
}

\author{
Mei Huang ${ }^{1, *}$, Jao Rao ${ }^{1}$, Shaodong Song ${ }^{1}$, He Wang ${ }^{1}$, Gangyu Chen ${ }^{1}$, Zhihua Kang $^{1}$, Feng Zhang ${ }^{1}$, Jieqiong Wang ${ }^{1}$, \\ Jiruo Ye ${ }^{1}$, Kun Feng ${ }^{1}$, Bo Lu ${ }^{1}$, Bo Huang ${ }^{1}$, Chao Wang ${ }^{1}$, Mingwei Wang ${ }^{1}$, Weimin Xuan ${ }^{1}$, Lieying Rao ${ }^{1}$, Qing Li $^{1}$, \\ Xiaohui $\mathrm{Mao}^{1}$, Xuru Duan ${ }^{1}$, Yong Liu ${ }^{1}$
}

${ }^{1}$ Southwestern Institute of Physics, P.O. Box 432, Chengdu, China

\begin{abstract}
A research has been conducted to develop an 8MW electron cyclotron resonance heating and current drive (ECRH/ECCD) system on HL-2M tokamak. The ECRH system compromise eight 1MW gyrotrons, eight evacuated transmission lines and three launchers. The main purpose of the ECRH system was to suppress the neo-classical tearing modes and control the plasma profile. This paper presents an overview of the design and studies performed in this framework. Some primary test results of the critical components have been released in this paper, e.g. polarizers, power monitor and fast steering launchers.
\end{abstract}

\section{Introduction}

Electron cyclotron Resonance Heating and Current Drive (ECRH/ECCD) system is employed worldwide for plasma heating and control on fusion research devices, with the merit of remote steering, localized heating and current drive etc. ${ }^{[1-3]}$ ECRH also played a very important role on HL-2A tokamak during the last decade, such as plasma heating, MHD instability control, assisted startup, real-time TM suppression, transport study, and so on ${ }^{[4-9]}$ In the next several years, the HL-2A tokamak will be upgraded to HL-2M, which has larger vacuum vessel and higher performance of plasma. ${ }^{[10]}$ The major radius of HL-2M will be $1.78 \mathrm{~m}$ and minor radius $0.65 \mathrm{~m}$. The maximum toroidal magnetic is expected to be $2.2 \mathrm{~T}$ and plasma current is about 2.5MA. For the HL-2M tokamak, ECRH/ECCD system will also be acted as one of the key plasma heating method for central electron heating, current profile control and NTM suppression.

Since the HL-2M will be operated at $1.8 \mathrm{~T}$ normally and the biggest toroidal magnet field will up to $2.2 \mathrm{~T}$, the frequency of ECRH system is fixed at $105 \mathrm{GHz}$ and 140GHz. The ECRH system on HL-2M tokamak was designed to compromise eight $1 \mathrm{MW}$ gyrotrons (two of them are dual-frequency, the others are single frequency $105 \mathrm{GHz}$ ), eight evacuated transmission lines and three steerable launchers. Fig. 1 shows the sketch of the layout of ECRH system. All of the gyrotrons will be settled in the RF heating hall which is in the south of HL-2M tokamak hall. Three ports in the east of HL-2M, one equatorial port and two upper ports situated at the same vacuum segment, were allocated for ECRH launchers. For the launchers, care is principally taken to change the wave injection angle in poloidal direction in real time. A preliminary design of the transmission line routing has been performed, mainly focused on getting the best solutions of attenuation issues. The first plasma of HL$2 \mathrm{M}$ was expected to be discharged at the middle of 2018 . By then, 5MW EC power could be delivered into plasma according to the process schedule of the ECRH project.
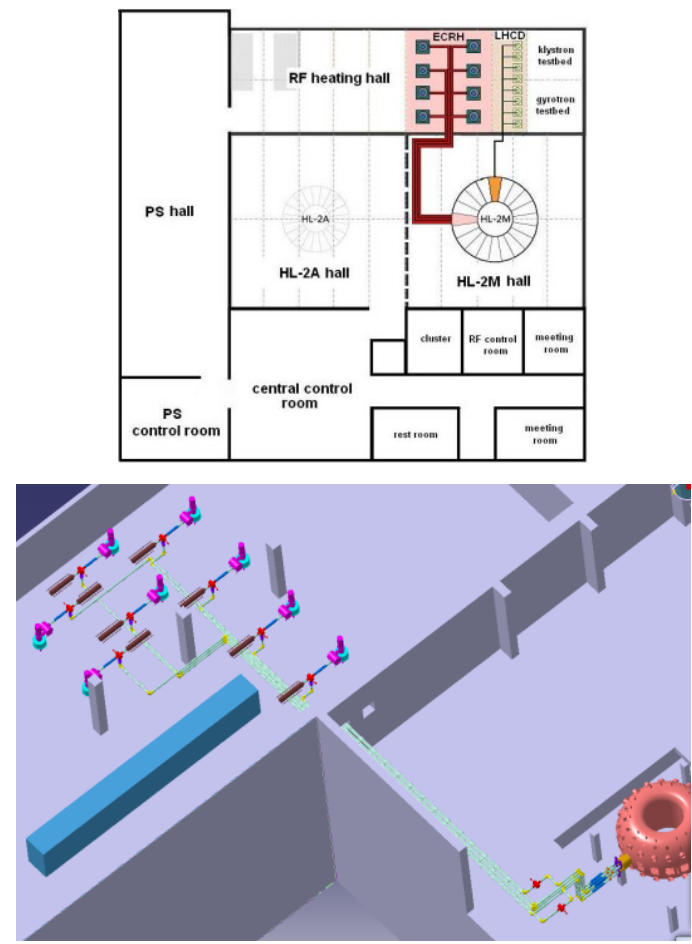

Fig. 1. Sketch of the layout of ECRH system and waveguide routing from the RF heating hall to the HL-2M tokamak hall

\footnotetext{
* Corresponding author: $\underline{\text { hm@swip.ac.cn }}$
} 


\section{Gyrotron commissioning}

All of the 1MW eight gyrotrons for HL-2M ECRH system are GYCOM gyrotrons. In order to commissioning the gyrotron flexibly, an independent test bed has been build last year in the RF heating hall, shown in Fig. 2. This test bed includes two different calorimeter dummy loads and body power supplies, one for short pulse and another for long pulse.

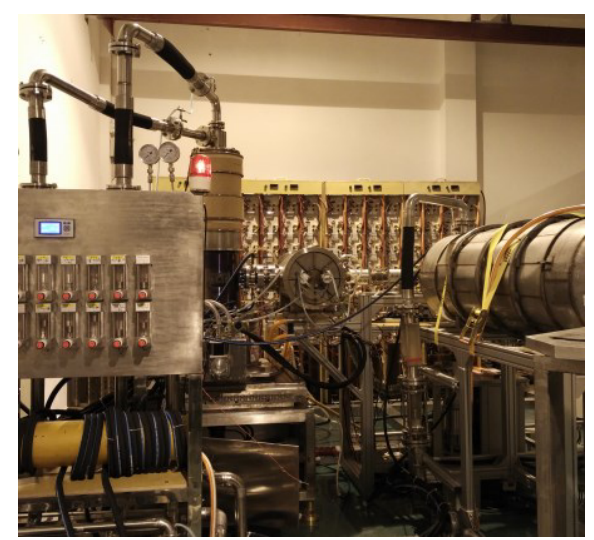

Fig. 2. Test stand for gyrotron commissioning

Based on the operation experience on HL-2A for many years, the basic control system was also constructed around PLC for the test bed and HL-2M ECRH system. The timing of gyrotron pulses as well as the launcher rotation angle could be controlled during the plasma discharge by fast control system. The interlock and interrupt circuits were taken into account to operate the ECRH system in safety for man and device. Same as the HL-2A ECRH system, Pulse Step Modulation (PSM) technology was adopted for the body HVPS of gyrotron which was fed by freewheel motorgenerator and four gyrotrons shared one HVPS. ${ }^{[1]}$ The output voltage of body HVPS could be adjusted from $20 \mathrm{kV}$ to $-80 \mathrm{kV}$, ripple less than $1 \%$ and switch-off time less than $10 \mu \mathrm{s}$. For convenience, a new body PSM HVPS only for one gyrotron and powered by intercity network was developed to fit for the operation requirement of the test bed. Further research of the body PSM HVPS are being carried out to increase the voltage modulation frequency up to $5 \mathrm{kHz}$ for NTM suppression. Simultaneous modulation of the collector voltage is necessary for deep power modulation. A new collector HVPS based on PSM technology was developed to achieve this aim. Tested with a resistor load, the maximum modulation frequency of it could reach $5 \mathrm{kHz}$. At the beginning of this year, the commissioning of two $105 \mathrm{GHz}$ gyrotrons has been fulfilled on this test bed. The hot test of transmission components will be put into effect on the test bed this year.

\section{Transmission line}

For the consideration of space limit and safety, a kind of evacuated transmission system carrying $\mathrm{HE}_{11}$ mode with low loss, high power capability, high transmission efficiency and broad bandwidth is designed and manufactured for HL-2M ECRH system based on the over-moded circular corrugated waveguide theory. ${ }^{[12-14]}$ The eight $1 \mathrm{MW}$ wave beams will be transported by eight evacuated transmission lines and be injected into the plasma through three launchers. The scheme of the eight transmission lines is shown in Fig. 3. Six of them are connected with the equatorial launcher, another two jointed with upper launchers. The lines will be about on an average 40 meters in length, including $63.5 \mathrm{~mm}$ waveguides, six or seven miter bends, bellow, DC break, pumping tee, switch and calorimeter dummy load. For the transmission system, some key issues have been considered, e.g. power attenuation, wave polarization and power measurement. At present, design and fabrication of all these transmission components have been finished.

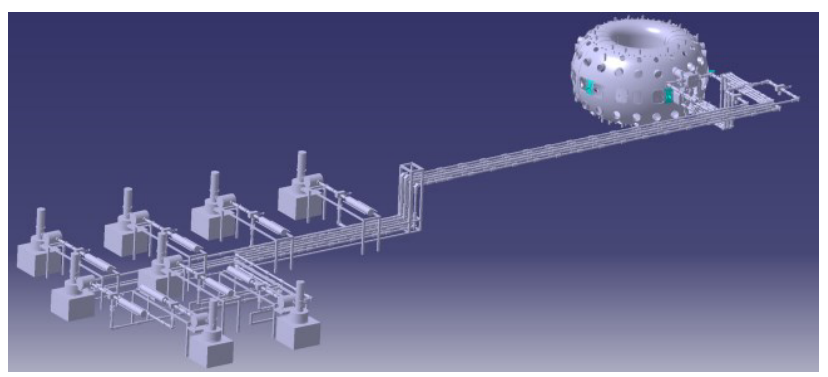

Fig. 3. Layout of transmission line for HL-2M ECRH system

\subsection{Attenuation analysis of TL}

Table 1. Loss of transmission line at different frequency

\begin{tabular}{|c|c|c|c|}
\hline \multicolumn{2}{|c|}{ Loss } & $140 \mathrm{GHz}$ & $105 \mathrm{GHz}$ \\
\hline \multirow{3}{*}{ Ohm (dB) } & $\begin{array}{c}\sim 30 \mathrm{~m} \\
\text { corrugated WG }\end{array}$ & $2.58 \mathrm{e}^{-3}$ & $3.99 \mathrm{e}^{-3}$ \\
\hline & 4 flat mirrors & $\begin{array}{c}2.56 \mathrm{e}^{-2} \sim \\
5.08 \mathrm{e}^{-2}\end{array}$ & $\begin{array}{c}2.20 \mathrm{e}^{-2} \sim \\
4.40 \mathrm{e}^{-2}\end{array}$ \\
\hline & 2 polarizers & $\begin{array}{c}2.56 \mathrm{e}^{-2} \sim \\
5.12 \mathrm{e}^{-2}\end{array}$ & $\begin{array}{r}2.20 \mathrm{e}-2 \sim \\
4.40 \mathrm{e}^{-2}\end{array}$ \\
\hline \multirow{3}{*}{$\begin{array}{l}\text { Coupling } \\
\text { (dB) }\end{array}$} & TEM $_{00}$ to $\mathrm{HE}_{11}$ & $8.8 \mathrm{e}^{-2}$ & $8.8 \mathrm{e}^{-2}$ \\
\hline & $0.2^{0}$ tilt & $1.36 \mathrm{e}^{-2}$ & $0.77 \mathrm{e}^{-2}$ \\
\hline & $\begin{array}{c}2 \mathrm{~mm} \text { axial } \\
\text { offset }\end{array}$ & $2.08 \mathrm{e}^{-2}$ & $2.08 \mathrm{e}^{-2}$ \\
\hline \multirow[b]{2}{*}{$\begin{array}{l}\text { Misalignment } \\
\text { (dB) }\end{array}$} & $0.2^{0}$ tilt & $1.43 \mathrm{e}^{-2}$ & $0.77 \mathrm{e}^{-2}$ \\
\hline & $\begin{array}{c}2 \mathrm{~mm} \text { axial } \\
\text { offset }\end{array}$ & $2.48 \mathrm{e}^{-2}$ & $2.48 \mathrm{e}^{-2}$ \\
\hline \multirow{2}{*}{$\begin{array}{l}\text { Gap between } \\
\text { WG(dB) }\end{array}$} & 6 miter bends & 0.166 & 0.18 \\
\hline & $\begin{array}{c}\sim 10 \mathrm{~mm} \text { other } \\
\text { gaps }\end{array}$ & $4.7 \mathrm{e}^{-3}$ & $7.2 \mathrm{e}^{-3}$ \\
\hline \multicolumn{2}{|c|}{ Total (dB) } & $\begin{array}{c}0.386 \sim 0.44 \\
(6.9 \% \sim \\
7.8 \%)\end{array}$ & $\begin{array}{c}0.384 \sim \\
0.428 \\
(7 \% \sim \\
7.7 \%)\end{array}$ \\
\hline
\end{tabular}

The losses at different frequency, $105 \mathrm{GHz}$ and $140 \mathrm{GHz}$, in the transmission line have been estimated theoretically. The losses are mainly caused by ohmic attenuation and mode conversion and the mode conversion losses are mainly caused by coupling, misalignment and gaps. ${ }^{[15-16]}$ Normally, ohmic attenuation is inherent and very low. And the attenuation of mode conversion are the key parts. The analysis results are presented in Table 2 . It can be seen that the transmission efficiency is about $92 \%$. 


\subsection{Wave polarization control}

Two polarizers will be integrated on the miter bends to control the wave polarization. The polarizers could be rotated fast.

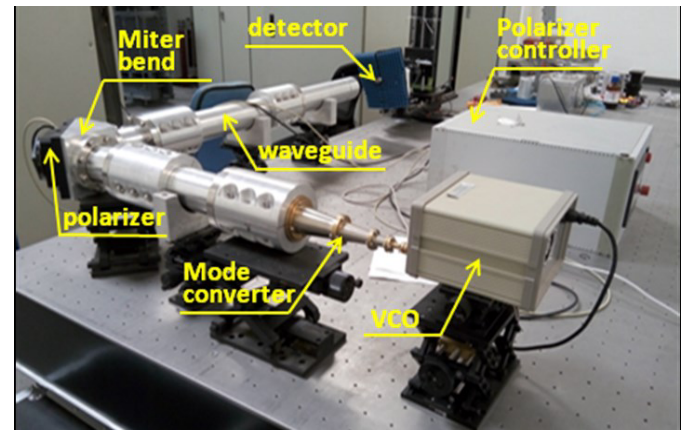

Fig. 4 Fast rotatable polarizer and laboratory test bed for polarization measurement of polarizers

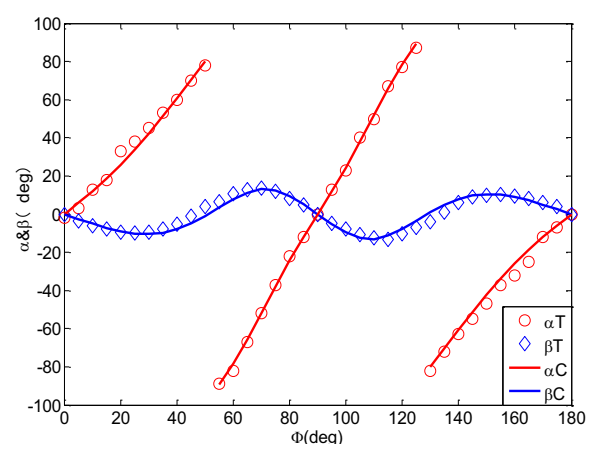

(a)

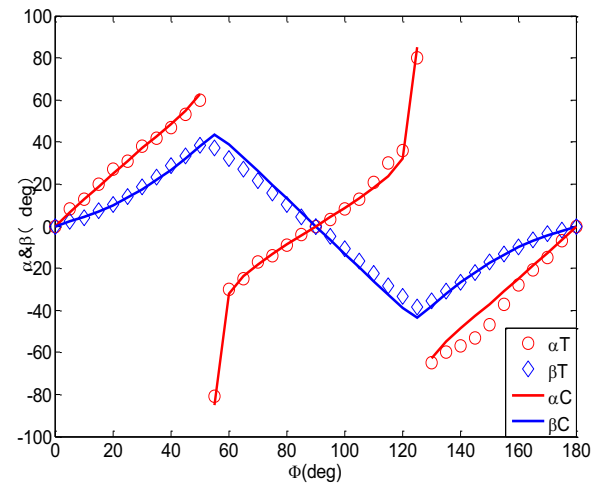

(b)

Fig. 5 Polarization parameters of the theoretical simulation results and cold test results for (a) the linear polarizer and (b) the elliptical polarizer, $\alpha C$ and $\beta C$ represent the calculation results, $\alpha T$ and $\beta T$ are for the low power test results, $\Phi$ for polarizer rotation angle

The two optimized polarizers are designed for single frequency by a simple and rigorous way. ${ }^{[17]}$ Arbitrary polarization of wave could be obtained by rotating these two polarizers. So the desirable mode could be excited for high coupling efficiency between EC waves and plasma when the millimeter waves injected into plasma obliquely. The cold test of these two polarizers have been explored and the experimental results are consistent with the theoretical simulation results nicely which illustrate that both the design and test method are reasonable. ${ }^{[18]}$ The laboratory test bed for measurement the ellipticity $\beta$ and axis rotation angle $\alpha$ is shown in Fig.4 and test results are shown in Fig.5. A study of polarization control strategy which are suitable for double frequency, $105 \mathrm{GHz}$ and $140 \mathrm{GHz}$, are on-going, makes it unnecessary to replace the polarizers in the transmission lines when the gyrotrons operated at different frequency.

\subsection{Power measurement}

Two power monitors are planned to be settled on the miter bends to measure the wave power. One is located near the gyrotron and another near the launcher, not only to estimate the transmission efficiency but also to follow the operation status of the gyrotrons. In order to validate the feasibility of the design and machining process, a $68 \mathrm{GHz}$ power monitor for HL-2A ECRH system was manufactured and checked during the plasma heating experiments at first, shown in Fig. 6.
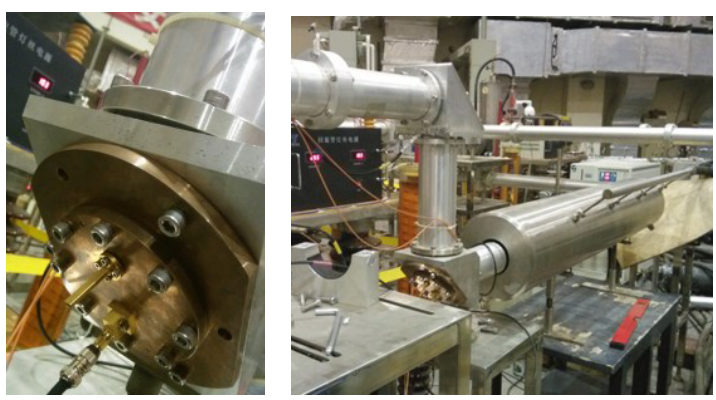

Fig. 6 Directional coupler settle on miter bend and calibrated by calorimeter dummy load

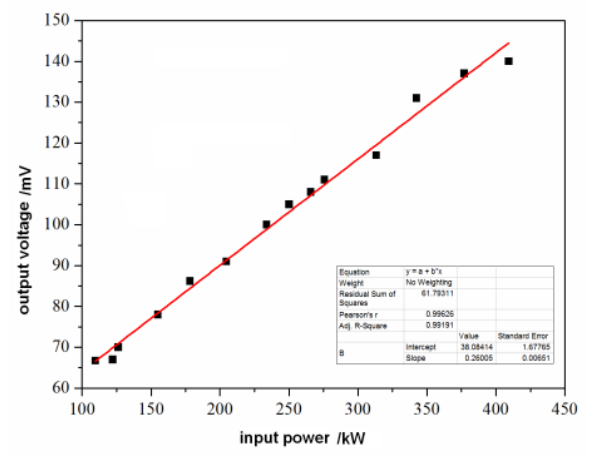

(a)

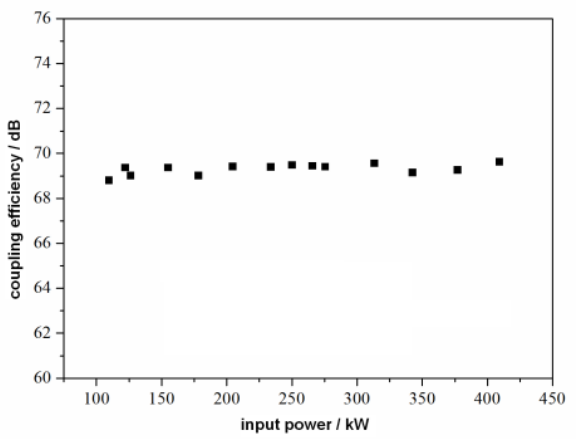

(b)

Fig. 7 (a) Dependence of output voltage of detector on input power of directional coupler and (b) the coupling coefficient of directional coupler: $-69.3 \mathrm{~dB}$ 
The power monitor has been calibrated by the calorimeter dummy load. It can been seen from the Fig. 7 (b) that coupling coefficient was about $-69.3 \mathrm{~dB}$ at different wave power. Fig. 7(a) shows the dependence of the output voltage of detector on the power measured in the dummy load. wave power and the linearity between input power and coupling output power is perfect. An $105 \mathrm{GHz}$ monitor has been produced in the same way as $68 \mathrm{GHz}$ monitor and the high power test results will be released in this year. A research for directional coupler with two-row-hole which could measure the wave power and wave polarization at the same time is proceeding.

\section{Launcher}

The three launchers of HL-2M ECRH system are one Equatorial launcher(EL) for $6 \mathrm{MW}$, one upper launcher(1\#UL) for $2 \mathrm{MW}$ and one upper launcher(2\#UL) for $1 \mathrm{MW}$. They have different functions, shown in Table 2.

Table 2. Performance of launchers for HL-2M ECRH system

\begin{tabular}{|c|c|c|c|}
\hline & EL & 1\# UL & 2\# UL \\
\hline Port Size & $450 \times 500$ & $\varnothing 300$ & $\emptyset 200$ \\
\hline Scheme & $3 \times 3$ & $1 \times 2$ & $1 \times 1$ \\
\hline Frequency & $105 \mathrm{GHz}$ & $105 / 140 \mathrm{GHz}$ & $105 \mathrm{GHz}$ \\
\hline Power & $6 \mathrm{MW}$ & $2 \mathrm{MW}$ & $1 \mathrm{MW}$ \\
\hline Pulse & $3 \mathrm{~s}$ & $3 \mathrm{~s}$ & $3 \mathrm{~s}$ \\
\hline Scan range & $\begin{array}{l}\text { Toroidal: }-20 \sim 20 \\
\text { Poloidal: }-20 \sim 14\end{array}$ & $\begin{array}{l}\text { Poloidal: }- \\
80 \sim-15\end{array}$ & $\begin{array}{l}\text { Poloidal:-90 - } \\
30\end{array}$ \\
\hline Function & $\begin{array}{l}\text { Plasma heating, } \\
\text { current drive, } \\
\text { assisted startup }\end{array}$ & $\begin{array}{c}\text { NTM } \\
\text { suppression }\end{array}$ & $\begin{array}{c}\text { NTM } \\
\text { suppression }\end{array}$ \\
\hline
\end{tabular}

The main functions of EL is plasma heating, current drive and assisted start-up. The purposes of two upper launchers are MHD control and NTM suppression. The EC power deposition location almost covers the whole cross section of plasma by rotating these three launchers, shown in Fig. 8. All of these three EC launchers enable millimeter-wave beam continuous scanning in poloidal directions in real time.

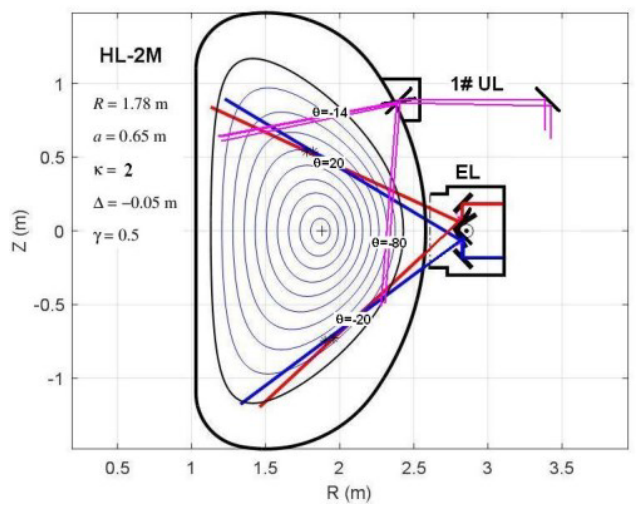

Fig. 8. Scan range of equatorial launcher and $1 \#$ upper launcher on the cross section of plasma
The 6MW EL has been fabricated and tested at the end of 2015, which could change the ECW injection angle at two-dimension. The outer structure of the plug-in unit and equatorial launcher is shown in Fig. 6.
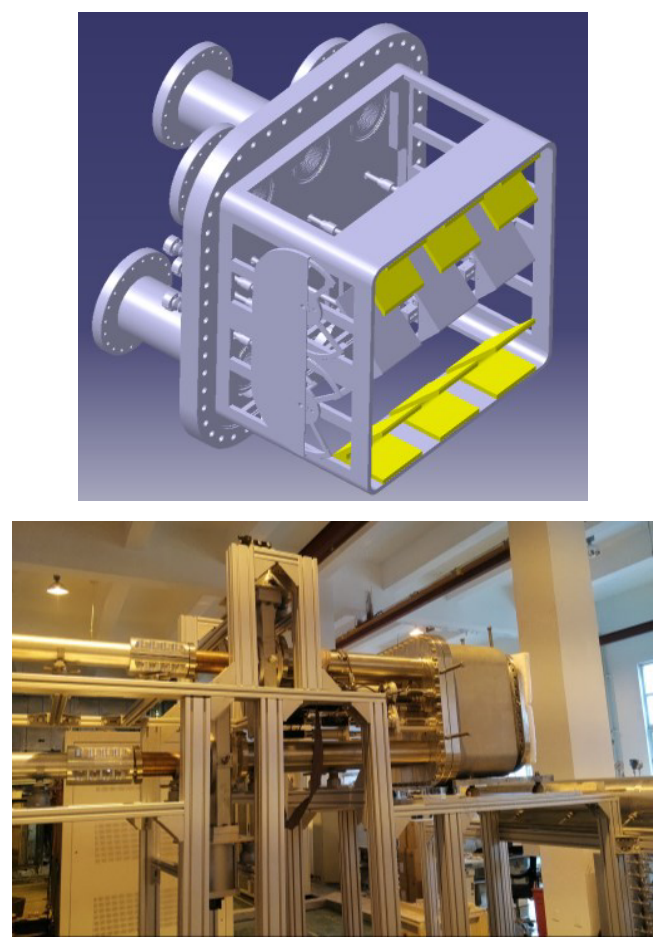

Fig. 9. Outer structure of the plug-in unit and equatorial launcher

Available space, port shape and port size of HL-2M tokamak suggest using two different kinds of steering mechanism for the poloidal and toroidal movement. In order to save space, wire rope and servo motor were applied in the toroidal direction in that the structure is simple and tight. In the poloidal direction, more complicated push rod framework were employed for NTM suppression in real time. A faster Kollmorgen linear motor was chosen to drive the push rods which can be controlled by NI-cRIO main controller. The performance of the EL has been tested. The total response time of control activities is less than $100 \mu$ s and the dynamic response time of mechanism for the full scan range is $45 \mathrm{~ms}$ in the poloidal direction, which can fully satisfy the requirement of changing the ECW power deposition during one plasma shot.

\subsection{Upper launcher}

The preliminary design of $1 \#$ upper launcher has been performed and the layout is shown in Fig. 10. Compared with the EL, the space for housing the reflective mirrors and steering mechanism is not enough because of the port size and shape. An extra extended segment was designed to solve this problem which caused the push rod becoming longer.

\subsection{Equatorial launcher}



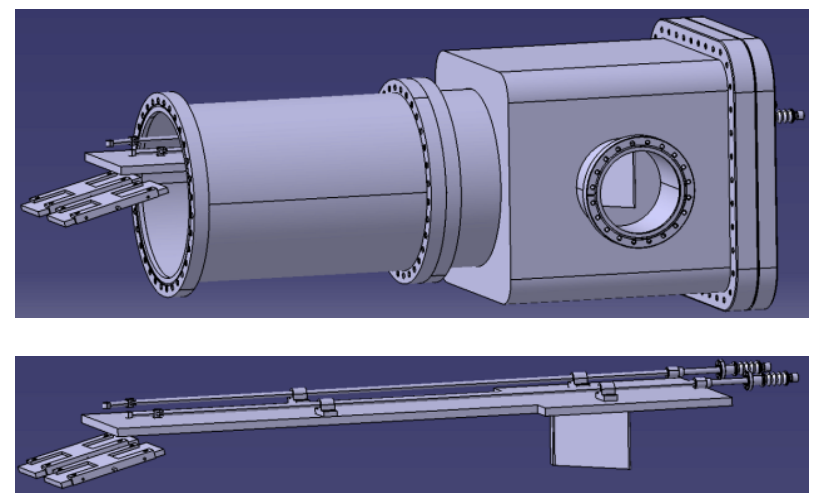

Fig. 10. Preliminary design of $1 \#$ upper launcher

A table test has been done to testify the performance of the steering mechanism. A prototype of the real steering mechanism and flat mirror were manufactured and assembled on the optical platform. Motor with higher qualities and the same main controller as EL were adopted in this case. The steering mechanism moved once every five minutes, up to one hundred times tests have been finished in a day. The maximum speed of motor reached 6000rpm and the mechanical structure maintained good condition. When the acceleration speed was set as $290000 \mathrm{rpm} / \mathrm{s}$, the response time of the movement for full range was $45 \mathrm{~ms}$. The test results show that the performance of $1 \#$ launcher could totally meet the demand of real time NTM suppression on HL-2M tokamak. The fabrication of $1 \#$ UL will be completed at the end of this year.

\section{Conclusion}

An 8MW ECRH system is expected to be constructed step by step on HL-2M. The conceptual design of this system has been undertaken. Most critical issues concerning transmission system and launchers have been studied and solved. The key components, such as PSM PS, fast rotable polarizer, power monitor and mirror steering mechanism, have been developed and tested. From the technical point of view, the behavior of these components could meet the physical objectives of HL$2 \mathrm{M}$ tokamak.

\section{ACKNOWLEDGMENTS}

Project is partly supported by the International Thermonuclear Experimental Reactor Special Fund of China (Grant No. 2013GB103000) and the National Natural Science Foundation of China (Grant No. 11175059). The authors appreciate all the staff and researchers contributing to the ECRH system on HL-2M and are grateful to the specialists of GYCOM, S. Kubo (NIFS, Japan) for fruitful discussion and suggestion.

\section{References}

1. V. Erckmann, U. Gasparino, et al., Plasma Phys. Control. Fusion 36, 1869 (1994)
2. B. Llyod, et al., Plasma Phys. Control. Fusion 40, A119 (1998)

3. M. Thumm. et al., 2003, Plasma Physics and Controlled Fusion, 45:A143

4. X.R. Duan, et al., Nucl. Fusion 50, 095011 (2010)

5. X.T. Ding, et al., Nucl. Fusion, 53, 043015 (2013)

6. W.L. Zhong, et al., Nucl. Fusion 53, 083030 (2013)

7. X.Q. Ji, et al., Chinese Physics Letters, 27, 6(2010)

8. X. Song, et al., IEEE Transactions on Plasma Science, 42, 3(2014)

9. M. Huang, et al., 3MW ECRH system and experiments on HL-2A, 37th EPS conference, Dublin, Ireland (2010)

10. Dequan Liu, et al., Fusion engineering and design, 96-97, 298-302(2015)

11. Xiaohui Mao, et al., IEEE Transactions on Plasma Science, 42, 1425-1429(2014)

12. M. Thumm, et al., Fusion Eng. Des., 26, 291 (1995)

13. Doane John L., et al., Propagation and mode coupling in corrugated and smooth-wall circular waveguides. Presented in Infrared and Millimeter Waves, Button K J, ED. New York: Academic, 13, 123 (1985)

14. Dragone C. Bell Syst. Tech. J., 56, 835(1977)

15. K. Ohkubo, et al., Int. J. Infrared Millim. Waves, 18, 23(1997)

16. Doane John L., et al., Int. J. Electron, 77, 489(1994)

17. D.H.Xia, et al., Review of scientific instruments, 84, 103504-103504(2014)

18. F. Zhang, et al., Journal of Infrared, Millimeter, and Terahertz Waves, 37, 572-581 (2016) 